\title{
Family presence in emergency: Attitude and belief among emergency health professionals in a Tertiary Care Hospital of Nepal
}

\author{
S Chaudhuri, G Malla, S Uprety, S Giri, AK Yadav, B Aryal \\ Department of General Practices and Emergency Medicine \\ B.P. Koirala Institute of Health Sciences, Dharan, Nepal
}

\begin{abstract}
Background: The emergency department of B.P Koirala Institute of Health Sciences, Dharan, a 700 bedded tertiary care centre provides all medical and surgical services, with easy access to patients by their family members during most of the resuscitation procedures. Complete privacy hence is not ideally maintained. Coping with emotional stress among the family members can be a gruesome experience and reactions from them can be unpredictable. Hence, health professionals are usually exposed to various emotions of the family members of these sick patients. Methods: It is a descriptive cross sectional study among the health professionals working in the emergency department. A sample size of 80 is taken over a period of 3 months. A semi-structured questionnaire leaflet was distributed and collected by the researcher. The attitude and belief was evaluated by 12 questions on the 5 point Liker scale and cutoff value being 3 . Points less than 36 were given as negative attitude towards the family presence and more being positive. Results: Out of 80 samples, 75 completed with a response rate of about $94 \%$. The majority belonged to age group $20-29$ years (70.7\%) age, among profession Nurses respondents were about $56 \%$. Male and Female respondent were about equal in numbers, qualification with undergraduate level was higher (73.3\%), with an experience of less than 1year being $40 \%$. Amongst the responders there is a positive attitude with increasing age, experience and qualification. Conclusion: The health professionals had a negative attitude towards the presence of family members during the resuscitation or invasive procedures. Hence with the ethnicity and cultural aspect of family their presence is well accepted.
\end{abstract}

Key words: Attitude, family presence, resuscitation

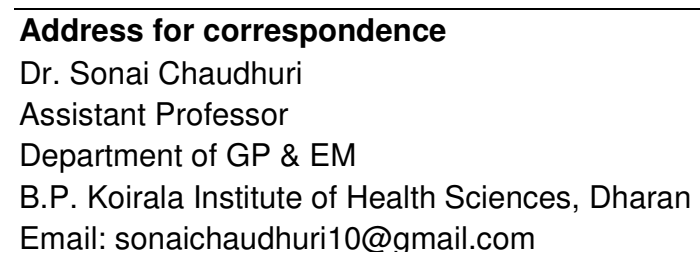




\section{Introduction}

The B.P. Koirala Institute of Health Sciences, Dharan, a 700 bed tertiary care centre providing all medical and surgical services to most of the eastern region of Nepal and adjoining states of India. Emergency department of this institute provides all the facility for the treatment of all life threatening conditions with appropriate resuscitation and possible life saving procedures.

A family is defined as a basic societal unit of two or more people related by genetic or interpersonal bonds, who have a commitment to nurture each other emotionally, physically and spiritually (Leske 1986; Picton 1995).

The anxious family members are usually worried and want the best care to be given to their near ones. In the emergency department of our institute there is minimal barrier from the resuscitation room and the visitor foyer. Complete privacy during resuscitation or any procedure is not ideally maintained. Coping with emotional stress among the family members can be a gruesome experience and reactions from them can be unpredictable. Hence, health professionals at our institute are usually exposed to various emotions of the family member of the sick patients where the outcome can be favorable or devastating. Presence of family members during medical procedures or resuscitation among paediatric patients have been well documented with several researches. ${ }^{1-5}$ The options when given of being present during these procedures parents opted to be present with their sick child. The more the invasive procedures the lesser the parents wanted to be present. However there were responses regarding presence of parents increased if their child were about to die or at their end stage of their diseases. But the final decision to be present or not, should be given to parents by their treating physician. ${ }^{1}$

The experience of health care providers and family of patients was studied by Meyers et al where they first used the family presence protocol developed by Emergency Nurses Association (ENA). ${ }^{6}$ Among the 96 healthcare providers and 39 family members, health care providers believed that the emotional and spiritual needs of the patient is fulfilled by the family presence, the condition of the patient is well understood and gave the opportunity to healthcare providers for a better environment to explain the disease condition to them. Performance and outcome were reported to be same by the healthcare provider response during family presence.

Various nursing organization have added "family presence" in their protocol for healthcare provisions. The American Nurses Association Code of Ethics for nurses includes primary responsibility of nurses as the" patient's place in the family or other network of relationship". 8 
Thus, provision of optimal care with human feelings is well expected from healthcare providers from all over the world to make a better place to live and work.

The study was designed to evaluate the attitude and acknowledge the concerns of the healthcare professionals towards the presence of family members during resuscitation/ invasive procedures in the emergency department.

\section{Methods}

The prospective descriptive study was conducted amongst the health professionals (doctors and nurses) over 3 months duration, in the emergency department of BPKIHS, Dharan, Nepal. The term "during resuscitation" refers to the time span during when the critically ill patients is brought to resuscitation area till the discharge or death of patient. ${ }^{7}$

Medical procedures include all the non invasive and invasive procedures done in the emergency for any life saving measures.

A respondent who had neutral response to all 12 questions scores a total of 36 , with higher numbers indicating an overall favorable attitude and lower numbers indicating an overall unfavorable attitude.

The questions are based on the survey done by Redley and Hood on medical staff's attitude in presence of family members during resuscitation and medical procedures. ${ }^{7}$
The statistical analysis was done using the SPSS software version 12. The variables are analyzed with a confidence interval of $95 \%$ using the Chi-square method and level of significance being $<0.05$. The ethical clearance was obtained from the IERB of B.P. Koirala Institute of Health Sciences. An open ended questionnaire leaflet was distributed by the researcher among the doctors and nurses personally after obtaining consent from each responder.

The anonymity of the responder was maintained by the use of identity card number provided by the institution. Age, sex, qualification and experience in emergency department was noted. The attitude was surveyed on basis of their response to questions like understanding the patient's condition, cardiopulmonary resuscitation being easier, patient management being more aggressive and effective, improvement of outcome of any procedures or resuscitation, stopping of resuscitation in case of death and emotional stress on health professionals in presence of family. Concerns of the staff regarding family presence was evaluated on the basis of misinterpretation of management procedures, disruption in the procedure, violence in emergency department, offending the family and medico legal issues. These questionnaires were then evaluated on the 5- point Likert scale (1strongly disagree, 5- strongly agree, and 3- 
neutral). A higher score indicated a more favorable attitude towards family presence.

For methodological rigor and elimination of bias, $50 \%$ of the questions were negatively framed, and $50 \%$ were positively framed. In negatively directed questions, the scorings were altered (5-strongly disagree, 1 - strongly agree and 3- neutral), during statistical analysis.

\section{Results}

Out of 80 samples, 75 completed the questionnaire with a response rate of about
$94 \%$. The basic characteristics of the study population was that the majority belonged to age group $20-29$ years $(70.7 \%)$, with a mean age group of 27.5 years. Among the professional group, nurses and doctors were $56 \%$ and $44 \%$ respectively. Male and Female respondent were about equal $(47.5 \%$ and $46.25 \%)$ respectively. Qualification with undergraduate level was higher $(73.3 \%)$ than post graduate level (23.6\%). The work experience in the emergency department of less than one year was $50 \%, 1-5$ years was $40 \%$ and more than 5 years was $10 \%$.

Table 1: Relation between mean score and demographic variables

\begin{tabular}{|c|c|c|c|c|c|c|}
\hline Character & Categories & $\begin{array}{l}\text { Mean } \\
\text { value }\end{array}$ & $\begin{array}{l}\text { Standard } \\
\text { deviation }\end{array}$ & Frequency & P-value & Remarks \\
\hline \multirow{3}{*}{$\begin{array}{l}\text { Age group in } \\
\text { years }\end{array}$} & $20-29$ & 34.68 & 4.051 & 53 & \multirow{3}{*}{0.910} & \multirow{3}{*}{ NS } \\
\hline & $30-39$ & 34.22 & 3.335 & 18 & & \\
\hline & $\geq 40$ & 34.75 & 5.123 & 4 & & \\
\hline \multirow{2}{*}{ Gender } & Male & 35.16 & 3.859 & 38 & \multirow{2}{*}{0.190} & \multirow{2}{*}{ NS } \\
\hline & female & 33.97 & 3.898 & 37 & & \\
\hline \multirow{2}{*}{ Profession } & Nurse & 35.10 & 3.811 & 42 & \multirow{2}{*}{0.193} & \multirow{2}{*}{ NS } \\
\hline & Doctor & 33.91 & 3.964 & 33 & & \\
\hline \multirow{2}{*}{ Qualification } & Undergraduate & 34.27 & 3.974 & 55 & \multirow{2}{*}{0.271} & \multirow{2}{*}{ NS } \\
\hline & Postgraduate & 35.40 & 3.648 & 20 & & \\
\hline Experience in & $<1$ & 34.83 & 3.996 & 35 & 0.266 & NS \\
\hline
\end{tabular}




\begin{tabular}{|l|l|l|l|l|l|l|}
\hline years & $1-5$ & 33.80 & 3.755 & 30 & \multirow{3}{*}{} & \multirow{2}{*}{} \\
\cline { 2 - 5 } & $>5$ & 36.00 & 3.830 & 10 & & \\
\hline
\end{tabular}

The relation with the mean score and the health professionals with an experience of demographic profiles had a slightly negative attitude with no statistical significance. department.

Although a neutral attitude was seen among

Table 2: Positive questionnaire response by health professionals

\begin{tabular}{|l|l|l|l|l|l|}
\hline \multicolumn{1}{|c|}{ Question } & $\begin{array}{c}\text { Strongly } \\
\text { disagree }\end{array}$ & Disagree & Neutral & \multicolumn{1}{|c|}{ Agree } & $\begin{array}{c}\text { Strongly } \\
\text { agree }\end{array}$ \\
\hline Understand the patient condition & $4(5.3)$ & $10(13.3)$ & $8(10.7)$ & $36(48.0)$ & $17(22.7)$ \\
\hline CPR being easier & $36(48.0)$ & $32(42.7)$ & $4(5.3)$ & $3(4.0)$ & $0(0.0)$ \\
\hline Provide encouragement & $9(12.0)$ & $33(44.0)$ & $22(29.3)$ & $8(10.7)$ & $3(4.0)$ \\
\hline $\begin{array}{l}\text { Management being aggressive } \\
\text { and effective }\end{array}$ & $4(5.3)$ & $25(33.3)$ & $8(10.7)$ & $32(42.7)$ & $6(8.0)$ \\
\hline $\begin{array}{l}\text { Improved outcome } \\
\text { procedure/resuscitation }\end{array}$ & $1(1.3)$ & $16(21.3)$ & $12(16.0)$ & $40(53.3)$ & $6(8.0)$ \\
\hline $\begin{array}{l}\text { Termination of resuscitation/ } \\
\text { procedure being easier }\end{array}$ & $15(20.0)$ & $31(41.3)$ & $7(9.3)$ & $20(26.7)$ & $2(2.7)$ \\
\hline
\end{tabular}

The respondents were positive on with family presence. Healthcare understanding the patients' condition better (48\%), management was aggressive and effective (42.7\%) and an improved outcome of any procedure or resuscitation (53.3\%) professionals were negative on CPR being easier (48\%), providing them encouragement $(44 \%)$, and termination of resuscitation or any procedure $(41.3 \%)$ with family presence. 
Table 3: Negative questionnaire response of health professionals

\begin{tabular}{|l|l|l|l|l|l|}
\hline \multicolumn{1}{|c|}{ Question } & $\begin{array}{c}\text { Strongly } \\
\text { disagree }\end{array}$ & Disagree & Neutral & \multicolumn{1}{|c|}{ Agree } & $\begin{array}{c}\text { Strongly } \\
\text { agree }\end{array}$ \\
\hline $\begin{array}{l}\text { Misunderstanding during } \\
\text { resuscitation }\end{array}$ & $1(1.3)$ & $18(24.0)$ & $15(20.0)$ & $34(45.3)$ & $7(9.3)$ \\
\hline Interference during treatment & $4(5.3)$ & $17(22.7)$ & $13(17.3)$ & $32(42.7)$ & $9(12.0)$ \\
\hline Emotional stress on HP & $2(2.7)$ & $15(20.0)$ & $13(17.3)$ & $37(49.3)$ & $8(10.7)$ \\
\hline Medico legal issues & $5(6.7)$ & $21(28.0)$ & $20(26.7)$ & $26(34.7)$ & $3(4.0)$ \\
\hline Violence in ED & $17(22.7)$ & $34(45.3)$ & $12(16.0)$ & $9(12.0)$ & $3(4.0)$ \\
\hline Family being offended by HP & $2(2.7)$ & $27(36.0)$ & $25(33.3)$ & $17(22.7)$ & $4(5.3)$ \\
\hline
\end{tabular}

Health professionals had positive response towards the concerns regarding misunderstanding the various activities done during resuscitation $(45.3 \%)$, family being interference during treatment $(42.7 \%)$ and emotional stress on health professionals (49.3\%). Although some responders agreed on medico legal issues (34.7\%) arising with family presence. Negative responses were observed regarding violence being more common $(45.3 \%)$ and offending family members by health professionals $(36 \%)$ in the emergency department.

\section{Discussion}

The questionnaire distributed among the health professionals addressed the various issues regarding family presence in the emergency department and their response showed their attitudes and concerns to them. Our results showed that the responders were higher among the age group of 20-29 years, undergraduate education and experience of less than one year, which implied that younger and less experienced resident doctors were more in direct interaction of the patient management and counseling. The emergency department of B.P. Koirala Institute of Health Sciences has 12 consultants and 30 resident doctors, the reason for such a varied difference in age and experience with their attitude and concerns with family presence. Nurses were major responders who all fell in this age group, experience and level of education.

Our health care providers were supportive and positive in understanding the patients' condition better, management being aggressive and effective and an improved outcome of any procedure or resuscitation in presence of family. The respondents agreed mostly that the treatment and outcome of the patient were more beneficial with family presence. Communication and the core 
problems of the patient were identified easily, while the invasive procedures and resuscitation were performed with confidence. No difference in opinion with professional difference could be found. Health professionals were satisfied with their attitude towards the approach and management to sick patients.

Although Duran et al suggested an overall positive attitude towards family presence amongst the health professionals. It suggested that nonresident doctors (interns, residents and fellows) were more positive about the family presence than the attending doctors. Nurses had an overall positive attitude amongst them. ${ }^{9}$ Baucher et al, showed an increased concern among nurses and doctors about their performance in invasive procedures, making them nervous and even upsetting the child with obstruction in the procedure. ${ }^{2}$

In most hospitals of Eastern Nepal the family members were always by the side of the patient since their arrival in the emergency department. This scenario can suggest their active role in their management along with health professionals. Hence negative responses were seen regarding violence being more common in presence of family and can be offending towards them by health professionals. Cardiopulmonary resuscitation was difficult to carry out, along with medico legal cases, which can also be a serious problem. In various studies ${ }^{1-7}$ it has been observed that family presence was either invited or kept away from the resuscitation or procedures involved in the emergency department.

These negative responses can be improved or changed by the health professionals with adequate counseling. Brief yet clear scenario of the ongoing patient management and possible outcome of the procedure can be explained to the family members. These measures can overcome the concerns in the health professionals so as to have an improved communication with the family members, who can provide a better emotional support to the sick patient.

Various suggestions during emotional outbursts leading to violence or disruption of the procedures can be made by the more experienced healthcare givers, which can be helpful. Making a waiting area in the emergency department can help, where the family members can be explained about the patient's condition in a calm place away from the resuscitation room where the aggressive actions takes place. Proper documentation along with each steps of management, decreases the risk of future medico legal cases which might arise. It even provides details in cases of review of the management for mortality related violence.

Health professionals working in the emergency department are mostly under 
physical and emotional challenges. They are overtly stressed with various issues like patient management, meeting bench mark performances, counseling and most importantly being humanely patient in their routine duty. This concern was also seen in our study. Their attitude towards the patient as a human being can sometimes be just another clinical challenge for them. Empathy can be lost and just be a stereotyped professional duty only. Studies on emotional stress on health professionals showed their increased concern during their management. ${ }^{7}$ Staff concerns can be addressed with occasional encouragement from experienced professionals and training them with simulations in the emergency department. Reviewing of the most stressful events among the team can be beneficial and rewarding.

\section{Conclusion}

In our hospital setting, the family members are the most important integrated strength in patient management. They are the decision makers in the society for the clinical management of the patient in the hospital. Their presence is the key to all successful procedures and resuscitation taking place in the emergency department. Health professionals, with their concerns and attitudes are being increasingly positive in some aspects whereas, are negative on issues regarding violence and medico legal cases. Hence concerns of our health professionals are being addressed by making an improved environment with much less stress in their performance and with improved patient management.

\section{References}

1. Boie ET, Moore GP, Brummett C, Nelson DR. Do parents want to be present during invasive procedures performed on their children in the emergency department? A survey of 400 parents. Ann Emerg Med. 1999; 34:70-74.

2. Bauchner H, Waring C, Vinci R. Parental presence during procedures in an emergency room: results from 50 observations. Pediatrics. 1991; 87:544548.

3. Haimi-Cohen $\mathrm{Y}$, Amir J, Harel L, Straussberg R, Varsano $\mathrm{Y}$. Parental presence during lumbar puncture: anxiety and attitude toward the procedure. ClinPediatr. 1996; 35:2-4.

4. Mangurten JA, Scott SH, Guzzetta CE, et al. Family presence: making room. Am J Nurs. 2005; 105:40-48.

5. Powers KS, Rubenstein JS. Family presence during invasive procedures in the pediatric intensive care unit: a prospective study. Arch Pediatric Adolescent Med. 1999;153:955-958. 
6. Meyers TA, Eichhorn DJ, Guzzetta CE, et al. Family presence during invasive procedures and resuscitation. Am J Nurs. 2000; 100:32-43.

7. Redley B, Hood K. Staff attitudes toward family presence during resuscitation. Accid Emerg. Nurs. 1996;4:145-151.

8. American Nurses Association. Code of Ethics for Nurses with Interpretive
Statements. Silver Spring, Md: American Nurses Association; 2000.

9. Duran $\mathrm{CR}$, Oman $\mathrm{K}$ et al. Attitude towards and belief about family presence: A Survey of Healthcare providers, patients' families and patients. American journal of critical care. 2007; 16:3. 